\title{
Knowledge and the family firm through generations: A knowledge-based approach in various geographic contexts
}

\begin{abstract}
This study examines the significance of knowledge, how it is created, and more specifically, its evolution and beneficial changes to the firm through the generational process from the perspective of the knowledge-based view (KBV) of the firm. Drawing from this theory, and its associations with the study's findings, a theoretical framework is proposed to enhance the understanding of knowledge in the context of family firms' generational processes. The study draws from data gathered among five family firms operating in both Northern and Southern Hemispheres. Overall, knowledge was created through previous experiences, accumulation of and conversion of explicit knowledge into tacit knowledge. The benefits of knowledge accumulation and sharing were multiple, including through efficiencies, new product development, or building business resilience. These findings also were associated with the KBV of the firm, for instance, in the added value added that stems from knowledge creation and operationalization, particularly through tacit knowledge.
\end{abstract}

Keywords: Family firms, knowledge, knowledge-based view of the firm, crosscountry sample.

\section{Introduction}

Family firms or businesses "in which multiple members of the same family are involved as major owners or managers" (Miller et al., 2007, p. 836), play a key economic role (Poza \& Daugherty, 2014; Prencipe et al., 2014) within their regions and potentially globally. One fundamental way for family firms, and overall for many organisations (Goh, 2016), to achieve a competitive advantage is through the maximisation and operationalisation of knowledge (Boyd et al, 2015). Not surprisingly, various dimensions related to knowledge within family firms have been discussed in the contemporary academic literature. These dimensions include knowledge integration (Chirico \& Salvato, 2008), organizational learning (Zahra 2012), transmitting and transferring knowledge across generations (Boyd et al, 2015; Giovannoni et al., 2011), knowledge sharing (Cunningham et al., 2016; Woodfield \& Husted, 2017), and absorptive capacity (Andersén, 2015).

One key element of knowledge gathering is learning, which Zahra (2012) defines as a process by which groups, organisations or individuals acquire knowledge through training, experience, analysis, experimentation or instruction. Zahra (2012) posits that learning can influence those involved, notably, through changes in behaviour or decision rules, and recognizing the limited understanding "of how organizational learning influences family firms' entrepreneurship" (p. 52). A review of recent family business literature suggests that this and associated gaps continue to exist. For example, Hernández-Linares, Kellermans, and López-Fernández (2018) revealed limited knowledge concerning the relationships between learning, entrepreneurial, and market orientation "in a family business context" (p. 192).

Indeed, more evidence on organisational learning within family firms could be insightful for academics and for industry stakeholders. For example, such research could help explain the extent to which learning processes of the family business ownership affect or influence the rest of the business.

Literature gaps have also been identified in other dimensions that concern family business research. For instance, and associated with the present study, Fletcher et al. (2016) contend that, despite calls for use and improvements, the potential of qualitative research has not been 
maximised in the area of family businesses. Thus, there appears to be an over-emphasis or a dominance of quantitative methods (Nordqvist et al., 2009) to explore different aspects of family entrepreneurship, even when numerous critical, and until now unanswered questions could be best addressed through a qualitative methodology (Reay \& Zhang, 2013).

Another knowledge gap in the family business literature is the glaring absence of research focusing on multiple geographic settings, which could help identify similarities or differences, for example, in how knowledge is developed, sharer, or operationalised among family firms.

The present study addresses these knowledge gaps, and therefore contributes to the family firm literature in several forms. First, it responds to the above calls for more studies employing a qualitative methodology, gathering data through field research, with face-toface, unstructured interviews as the primary source of data collection. Second, partly aligned with Zahra's (2012) concern, the study seeks to understand the impact of knowledge on the family firms. In particular, the study is concerned with how knowledge develops within the firm, and how it manifests itself through different family generations. This generational process can be understood as transferring "ownership rights and leadership control to the next family generation" (Letonja and Duh, 2016, p. 213).

Third, in contrast to mainstream family business research, the study takes a cross-country perspective, gathering data among family enterprises operating in various countries (Australia, Italy, Peru, United Kingdom and Uruguay). Finally, the study also seeks to contribute theoretically, drawing from the knowledge-based view (KBV) of the firm (e.g., Grant, 1996, 2002). Emerging associations between this theory and the findings will be presented in a proposed theoretical framework, which partly addresses a theoretical gap, in that "family business researchers often experience theory specification... constraints" (Astrachan et al., 2014, p. 119).

The following section presents the literature review, and discusses the proposed theoretical background of the research. Subsequently, the methodology provides the rationale for the methods and approaches chosen, examining for instance, the case study and the qualitative focus utilised for this study. Furthermore, the results section presents the findings that address the two key research questions. Thereafter, the discussion section identifies linkages between the KBV and the findings, and proposes a theoretical framework (Figure 1). Finally, the conclusions summarise the key aspects of the study, discuss its theoretical and practical implications, acknowledges its limitations, and proposes avenues for future research.

\section{Literature Review}

\subsection{Theoretical background}

The various links between the study's aims and objectives, which essentially focus on knowledge within a family context and the KBV strongly suggest the usefulness of examining the knowledge dimension through this theoretical foundation. From an academic context, the KBV depicts a convergence of various streams of research, including the resource-based theory of the firm (Grant, 1997).

Among other forms of knowledge, in-house technological knowledge is underlined as one of firms' resources (Wernerfelt, 1984), while tacit knowledge is an illustration of valuable, difficult-to-transfer know-how (Conner and Prahalad, 1996). Tacit knowledge can be shared directly with other individuals, and absorbed or learned through practice, imitation, or observation (Nonaka \& Takeuchi, 1995). Tacit knowledge can evolve from explicit knowledge, which is systematic and formal, can be easily shared and communicated, including in scientific formulae or computer programs (Nonaka \& Takeuchi, 1995). In the same vein, one central theme in strategic management recognises privately held knowledge as "a basic source of advantage in competition" (Conner and Prahalad, 1996, p. 477). 


\subsection{The development of knowledge and family firms}

Given its most fundamental tenets, for instance, in that it contributes to the analysis of how organisations acquire, create, protect, transfer or apply knowledge (Cabrera-Suárez et al., 2001), the KBV represents a powerful medium to understand the transfer and nature of knowledge among family businesses. The theory also emphasises the significance of colocating knowledge and decision making (Grant, 1997), which has implications for family enterprises, notably, in how knowledge flows through the firm, from the ownership to its employees.

Thus, the present study is concerned with the following fundamental research question:

- How is knowledge developed within the family firm?

The extant academic family business literature provides insights that are associated with the above question. For example, and associated with the discussion of tacit knowledge, and as Hernández-Perlines (2018) found among Spanish family firms, knowledge absorption is fundamental for their competitiveness. In examining the impact of absorptive capacity, or those organisational routines that contribute to firms' acquisition, assimilation, transformation and exploitation of knowledge (Zahra and George, 2002), Hernández-Perlines (2018) ascertained that these routines had a positive moderating effect on family firms' entrepreneurial orientation, and therefore on their international performance. In an attempt to understand the mediating mechanisms in the relationships between absorptive capacity and performance among family firms in India, Chaudhary and Batra (2018) hypothesised an indirect relationship between the two. Moreover, they confirmed that links between absorptive capacity and strategic firm orientation result in firms' improved performance. For example, following three key elements of absorptive capacity, notably, acquiring, assimilating and exploiting knowledge in the form of "crafting an entrepreneurial posture and technology augmentation" (Chaudhary and Batra, 2018), small family firms can be a step closer to achieving sustained competitive advantage.

Chirico and Salvato's (2016) research supports the notion that a more limited hierarchy within the composition of the family firm allows for flow of knowledge. Indeed, their research revealed that collective and social processes of knowledge recombination and interaction are necessary in order "to blend the knowledge bases of individual family members" (p. 219), which is required by both implementation and identification of entrepreneurial ideas. Chirico and Salvato (2016) therefore recognise the role of knowledge internalisation, a process that allows family members to leverage individual knowledge mutually to uncover new product objectives. These authors' findings have associations with the KBV. For example, in line with Grant (1997, 2002), knowledge internalisation can be a key strategic source for the family firm, and further strengthened by family members' specialisations and specialised knowledge, which can also contribute to create, develop, or improve products and services.

Chirico and Salvato's (2016) study resonates with that of Chirico and Nordqvist (2010), who also underlined the strategic significance of knowledge. Chirico and Nordqvist (2010) found that knowledge was mainly enhanced by a high level of emotional involvement and social capital, with implications for creating value across generations of the family firm.

In yet another contribution pertaining to knowledge in the domain of family firms, Chirico (2008) presents a model that identifies two fundamental factors leading to knowledge accumulation and to enabling firm longevity. In agreement with Chirico and Nordqvist's (2010) research, Chirico (2008) identifies emotional factors, which include trust between family members, and is enhanced through face-to-face interactions; commitment to the 
business and psychological ownership of the family firm (Chirico, 2008). Under openness factors, Chirico (2008) acknowledges the importance that the experience of family members working or even taking training courses outside the family firm, as well as employing nonfamily members can have on creating an advantage.

The factors Chirico (2008) identifies have clear links with the KBV. Fundamentally, internal exchanges based on family member interactions, or through their commitment and sense of ownership can equip the firm with internal knowledge, which then becomes unique to the family business. At the same time, being able to gain external exposure allows firm members to absorb, assimilate, and capture other forms of information that can contribute to a continuous supply of explicit knowledge, further build tacit knowledge, and renew and revitalise the firm.

Together, the above notions support the following proposition:

Proposition 1: Accumulated experiences by members of the family firm, together with social exchanges that include interactions among family members and their interaction with external parties are significant in the development of knowledge within the participating family firms.

\subsection{Knowledge and its manifestation across generations of family members}

Despite the potential failure of family firm succession over time, achieving long-term continuity through new generations inheriting or taking over the business is strategically crucial (Letonja \& Duh, 2016; Williams \& Mullane, 2019). Consequently, the following additional research question will be addressed:

- How does knowledge manifest itself from one generation to the next?

Academic entrepreneurship literature discusses the importance of understanding knowledge dissemination and transfer among different generations of the family firm (e.g., Boyd \& Royer, 2012; Letonja \& Duh, 2016). Although not specifically addressing family firms, part of this literature implies strong associations between the above dimensions and the KBV, for instance, through the sharing and absorbing of explicit knowledge (Nonaka \& Takeuchi, 1995). Similarly, and as research conducted among company managers found (Foos, Schum, and Rothenberg, 2006), there is a relationship between trust and tacit knowledge exchanges. Such relationship can also apply within the context of members of family firms, who arguably share strong trustworthiness and family ties, with implications for the successful transfer of knowledge (Letonja \& Duh, 2016).

Earlier research (Cabrera-Suárez et al., 2001) postulates that the succession process is a key challenge facing family businesses. One fundamental reason is related to the ability of firm successors to gain adequate knowledge and skills that are essential to keep or enhance the firm's organisational performance (Cabrera-Suárez et al., 2001). For instance, while parents can play the essential role of mentors for family firm successors (Cater and Justis, 2009), the early participation of children in the family business can lead to in-depth levels of tacit knowledge associated with the business (Danes et al., 2009; Sirmon \& Hitt, 2003). Indeed, multiple and different generations of family members involved in the firm can bring fresh experiences and insights, and overall new knowledge that can promote innovation.

Similarly, diversity in knowledge drawn from different generations of family business members can enhance various firm dynamics, particularly when the involvement of family members is moderate (Sciascia et al., 2013). In contrast, high involvement of generational family members can at times be counterproductive, as it can lead to relationship conflicts (Sciascia et al., 2013). Thus, understanding the significance of knowledge transfer during succession processes can help firms to maintain or improve their competitive advantage (Cabrera-Suárez et al., 2001). Given the importance of knowledge gathering, accumulating 
and transferring across generations of the family firm, the following second proposition is presented:

Proposition 2: Knowledge across family firm generations among the participating firms manifests itself predominantly through its dissemination from earlier generations, as well as through its continuous growth, notably, undertaken by current and incoming generations of family members.

\section{Method}

The data collection period for this study spans between the end of 2014 through 2017. Discussions with representatives of chambers of commerce, individual businesses, and government agencies contributed to the identification of the five model family firms. These firms, all of which were crucial to the present research, were selected based upon the following criteria:

- They were family businesses that had operated for at least one decade.

- They played a leading role in their industries locally (regionally) or nationally.

- Various family members from various age groups were involved in the family, thus, suggesting the potential for firm succession by different family members.

In responding to calls for more qualitative research (Fletcher et al., 2016; Reay \& Zhang, 2013), to address theoretical constraints (Astrachan et al., 2014), or to employ a cross-country approach, the present study sheds more light on knowledge within family firms. Moreover, by associating the adopted theoretical foundation (KBV) and the findings, the study proposes a theoretical framework which explains and contributes to the understanding of how knowledge is developed, and how knowledge manifests itself through the firm's generations. To this end, the study examines the perspectives on knowledge among five family firms operating in the Northern and Southern Hemispheres. Thus, the unit of analysis, or the confined group of elements encompassing the object which is at the heart of the research (Gronn, 2002) is represented by the perceptions of family entrepreneurs from five different nations regarding knowledge development and its manifestation within the family firm.

In line with earlier family business research (e.g., Efferin \& Hartono, 2015; Zellweger \& Sieger, 2012), the study adopts a case study and qualitative approach. A case study has been defined as an in-depth empirical examination of a contemporary phenomenon (the actual case) within a real-life context (Yin, 2013). Case studies are appropriate when 'how' or 'why' questions are asked concerning contemporary events over which researchers have limited or no control, and rely on various sources of evidence (Yin, 2013). These sources include interviews, observations, and archival data (Eisenhardt, 1989), ultimately providing rich data from a range of sources to develop robust conclusions. In accord with various studies (e.g., Chirico, 2008; Sosna et al., 2010), the study's main data collection medium was interviews, and supported and enhanced by on-site observations and gathering of firm information (printed, online sources).

Complementing the chosen qualitative, case-study methodologies, an inductive approach to qualitative evaluation data is chosen. Thomas (2006) explains that the fundamental objectives of an inductive approach are to: a) summarise raw textual data in a summary, short format, b) create links between research objectives and findings emerging from the raw data, and c) "develop a framework of the underlying structure of experiences or processes that are evident in the raw data" (p. 237). In the present research, this third objective is illustrated through a proposed theoretical framework (Figure 1), which partly rests on the notions of the 
KBV and associated literature (Conner \& Prahalad, 1996; Grant, 1996, 1997, 2002; Nonaka and Takeuchi, 1995; Wernerfelt, 1984).

The focus and objectives of the study, which is aimed at gathering data from relevant individuals who are both knowledgeable and experienced family entrepreneurs provides the rationale for the methods and approaches. For example, a purposeful sampling method was adopted, with model firms being chosen for the research. This method entails the strategic selection of information-rich cases to investigate; by their characteristics, these cases will assist researchers in illuminating the question under examination (Patton, 2015). In addition, a constructivist approach was chosen. According to Mills et al. (2006), undertaking this approach requires, for instance, adopting "a position of mutuality between researcher and participant in the research process" (p. 8), as well as creating a sense of reciprocity between research and participants in co-constructing meaning.

The identified model family firms were initially contacted by email correspondence. In the message, the objectives of the research were presented, and at the same time, firms were invited to partake in the study mainly through an unstructured, face-to-face interview. All these five firms' ownership accepted the invitation, and be interviewed at their convenience. Data collection was undertaken with the five case studies in Uruguay (2014-2015), Western Australia (2015-2016), United Kingdom (2016-2017), Italy (2017), and Peru (2016-2017) through interviews, archival research and observations. One member of the research team, who is fluent in the languages utilised by participants (Italian, Spanish), travelled to each of the firms' premises, and conducted face-to-face interviews that ranged between 60 and 180 minutes, including on-site visits. All interviews were audio-recorded with participants' agreement. The interview protocol started with general questions about participants and their firms, and then fundamentally sought answers to the following key questions:

- How is knowledge developed in your firm? In what ways is it developed?

- How does knowledge manifest itself across generations in the case of your firm?

To reflect current discourse in the design of these questions, various sources discussing knowledge and the KBV of the firm in the context of family firms were consulted (e.g., Cabrera-Suárez et al., 2001; Chua et al., 2012; Chirico, 2008; Chirico \& Salvato, 2008; Patel \& Fiet, 2011).

The interviews were transcribed, translated and cross-checked by the members of the research team; this process allowed for more accuracy, transparency, and consistency of the data content. In accord with Elo et al. (2014), who posit that qualitative content analysis is generally employed when analysing qualitative data, this approach was used. Hsieh and Shannon (2005) conceptualise qualitative content analysis as a method to subjectively interpret content of text data, consisting of a "systematic classification process of coding and identifying themes and patterns" (p. 1278).

Through the process of content analysis, recurrent and prevalent issues were identified. These provided an opportunity to enhance the robustness of findings through saturation. Miles and Huberman (1994) define saturation as the point at which no further information can be uncovered through more data collection. Marshall et al. (2013) suggest that no general agreement exists on the number of interviews at which saturation occurs. Indeed, for the purposes of this study, the recurrent themes identified through the 5 case studies that are reported in here were saturated. Moreover, upon the fifth case study, no new issues were emergent from the data collection; this outcome not only included the examination of interview data, but also information drawn from archival sources and observations during the visits to the family firms. 
The data management software NVivo, version 11, a computer-assisted qualitative data analysis software (CAQDAS) (Sinkovics et al., 2008) was used to support the analysis process, for instance, in the design of part of Figure 1. The software further allowed the incorporation of archival and observation notes to be included in the identification of prevalent issues, thus, enabling a more robust analysis process as all data sources were easily accessible and collated for holistic review.

\title{
Basic demographic characteristics: Participants and firms
}

All participating firms had operated for at least a decade, were all involved in different industries, and all exported their products (Table 1). Participants had nearly (i.e. Italy1), or more than a decade of experience. In addition, the firms were in one way or another experiencing generational renewal, either through the second generation already taking full control of the family business (Italy1, Uruguay1), or becoming increasingly involved in the firm (second generation), as in the cases of Australia1, Peru1, and UK1.

Table 1 Here

\section{Results}

How knowledge develops within the family firm

Participants' extended comments underline that, overall, knowledge is created through a long process of hands-on experiences, internalisation of knowledge, and exposure, including by external learning, and building critical mass and networks. As the summary of this first dimension illustrates (Table 2), knowledge is fundamentally acquired through five different ways, with hands-on experience and networks/collaborations being the most instrumental. These dimensions also directly contributed to the acquisition of explicit knowledge, where for example, Australia1's comments clearly highlight the instinctive nature of knowledge building. Furthermore, after successfully running avocado production and marketing, a critical event occurred, in that the owners sensed a future product oversupply that inevitably would have negative consequences for the local industry and the firm:

\begin{abstract}
Because the avocado industry has been very successful in the southwest and people have continued to plant, that means that it takes a few years for these trees to come online, but as they come online the production increases... So when that happens, if you cannot build demand within the domestic market to grow at the same rate as production, you are then going to be in over supply. And if that happens you're gonna work a lot harder for a lot less money.
\end{abstract}

As a result, Australial's firm made various strategic decisions, which illustrate a clear path for knowledge creation and operationalisation, with clear implications for the firm's long-term survival and success. At an individual level, and supported by its expertise, the firm transformed itself. For instance, at a group level, the firm built networks with other Australian avocado producing firms with the goal of exporting to demanding and lucrative consumer markets. This finding is aligned with recent research among Australian family firms (Duarte Alonso et al., 2018), which reveals the importance of accumulated industry knowledge as a source of competitive advantage.

Despite the potential negative outcome of the growth in avocado production and resulting competition, Australial's case depicts what Cope and Watts (2000) refer to as "the power of positive critical incidents in terms of creating permanent change and development" (p. 124).

Another critical, albeit negative, event is illustrated by the 2002 foot and mouth disease outbreak, which severely affected UK1's previous livelihood, and conditioned its future entrepreneurial direction. Previous knowledge in food manufacturing (relishes, jams, spreads) 
of one co-owner and experience in the hospitality industry (a pub) of the second co-owner helped the family firm to stand on its feet: "Food was always something we were going to be fascinated with. It's always been a passion for both of us. We love trying new things, and mixing flavours, and experimenting." Thus, the nearly devastating event for the firm, and hands-on experience, coupled with trial and error in new product development were clear forms in which knowledge was developed. In addition, networks and collaborative efforts, for instance, with international partners, have paved the way, for instance, for potential issues after the advent of Brexit.

Lindh and Thorgren (2016) present the concept of critical event recognition, which they define as a cognitive process, whereby individuals deduce they are confronting "a critical learning point" (p. 525), which requires change in actions and thoughts. Clearly, this critical event transformed UK1, as it had to undergo a very challenging learning process in which knowledge was significantly accumulated and learning occurred over extended periods of time. This learning, however, became one of the pillars of the firm, as it helped the firm find its niche, and evolve, diversifying and increasing its international exposure.

Similar to the above cases, Uruguay1 accumulated extensive knowledge during its time as a maritime agency, which thrived as a supplier and provider to large vessels. Through a critical event manifested overtime due to intricate relationships and exchanges in interests in fishing and similar matters built over decades, the firm discovered a totally new dimension to business, which transformed its future:

Our father was provider of Soviet whaling ships that had their base in Uruguay (1962-1963)... and stopped in Montevideo on their route to Antarctica... in one of their last expeditions (1987-1988), a retiring scientist brought an information manual... In this manual, there were a series of studies indicating that Uruguay was one of the few places where scientists believed that sturgeons could develop and survive...

Table 2 Here

Knowledgeable by the previous networking experience, in the following years, the firm's owner travelled to Russia, and gathered more information, know-how, and equipment. In 1995, the first sturgeon eggs were brought for trial, and eventually, in 2000 the first commercial production of caviar was achieved, which represented the beginning of a total shift in the firm's business focus. These findings pertaining to Uruguay1 are in accord with recent SME research (Diehr \& Wilhelm, 2017), which found that seeking external sources of knowledge, including through networks with other firms, was fundamental for some firms possessing limited resources.

For Peru1, knowledge of various facets related to coffee, supplemented by drive and passion, provided the foundations for the firm to start in a very competitive industry:

... I liked this industry, I knew where to find suppliers, and the demands of the industry. On that basis, I decided to be in it as a way of life... you learn a lot instinctively; in fact, knowledge becomes part of yourself, of what you feel, and it cannot leave you anymore.

However, for the participant, a critical event illustrated by the arrival of a giant international player to Peru's consumer market represented a crucial change that would define the way in which the local industry operated:

...when they arrived, they helped the industry through the marketing of their concept. Very few other firms using horizontal distribution and marketing 
campaigns, remained in the industry. We, however, maintained our philosophy of very high consumer service and strong relationships with consumers...

Again, in agreement with Cope and Watts (2000), this case also demonstrates a positive critical event. Crucially, this event was seized by the firm, which, taking advantage of its wealth of knowledge and expertise of four decades, was able adapt to a new business philosophy and regime.

The gained insights and experiences from past activities and ventures, and the building of networks and social exchanges identified in the above findings provide strong evidence supporting Proposition 1.

\section{How knowledge manifests itself through the firms' generations}

The cases of all participating firms demonstrate that whether or not the family business had gone through generational renewal, knowledge was passed on, or was in the process of being assimilated by the new generations in various ways (Table 3). In particular, observations conducted during and after the interviews, and information gathered from some of the firms' websites and social media outlets identified the strong drive for passing such knowledge, and, for recipients, their ability to absorb, dissect, and in some cases further that knowledge.

For instance, in the case of Australia1, their son, still in his early 20s, had developed a strong interest in technology, which led to the creation of an application to help avocado farmers gather and store information about their business, including information associated with expenditures and orchard management. For Australia1, this evolution of knowledge, in that a new family member combines, complements, and extends the owners' industry expertise to a higher level, contributed to adding value to both the firm and its clients. Similarly, having accumulated knowledge and experience in various industries, from sales to cleaning, the son's fiancé became involved on a full-time basis, supporting the firm in marketing and in environmentally sustainable activities, such as decreasing wastage while maximising food production.

The case of Italy1 also exemplifies the evolution of knowledge across generations, underlining the importance of accumulating crucial knowledge since the 1970s, when the firm was established. Moreover, the involvement in the Prosecco Superiore industry by previous generations of the family set the foundation for the development of basic philosophies and business principles. In 2003, the children took over the family business. Through the growing popularity of the more standard type of Prosecco, the firm is building upon this success, and through knowledge-based principles, differentiating and positioning their product (Prosecco Superiore) at a higher end of the consumer spectrum. For instance, members of the firm were accumulating knowledge of ancient varietals, trying to rescue them to preserve a historic component of their region, and utilise the grapes in production. Furthermore, and similar to other participating firms (e.g., Australia1, Peru1), the respondent had brought a different set of skills to the company:

I graduated in jurisprudence, and was working in an office, and helped my brothers part-time. But we came to a point where... I decided to join them full time. I made the right choice because the world of wines is very interesting.

Now the participant was in charge of public relations, hosting visitors, and conducting marketing activities. In addition, the fact that "in the last few years, there has been an increase in professionalism in this industry" meant that the firm has had to address challenges and requirements continuously.

In addition to helping consumers discern the differences between standard and high-end Prosecco (Superiore), as product confusion was affecting the firm's brand image, as well as saving ancient grape varietals, the firm was also adapting to the unexpected event of a 
growing wine tourism phenomenon. This development demanded new knowledge, new skills, and consideration of a different strategic approach as opposed to earlier times when the main and sole focus was to produce sparkling wines.

Table 3 Here

While reflecting on the continuous developments of the firm throughout the decades, Peru1 recognised the importance of generational renewal: "my eldest son, who is an economist, also become involved. He too had other options to be involved in professionally, but was passionate and liked this industry." This event has coincided with new strategic options being considered. For instance, the firm developed a unique concept for Peru, in that it not only produces coffee, sourcing beans from dozens of micro-producers, but also directly liaises with customers by providing two small coffee shops:

...By having the shops, we have been successful because we were able to taste and trial different coffee varieties... We know the differences from blending different varieties of coffee to find a product that can address a trend in consumption. That you cannot see; you have to do it, it is evidential...

For UK1, the next generation represented by the family's two daughters, demonstrates the value of a complementing set of skills that extend the focus and impact of the firm. For instance, during two visits it was noticed that one of the daughters had completed courses, worked outside of the firm, and was then fully assimilated into the firm, taking responsibility for social media communication. Moreover, in assisting the firm's marketing manager, the family member was constantly absorbing new knowledge which was clearly reflected in dayto-day activities, particularly on the marketing side. She also attended trade fairs and visited customers both domestically (UK) and overseas, further building explicit knowledge that over time can result in tacit knowledge. The second daughter, on the other hand, was responsible for direct sales in one of the family's shops, thus, suggesting the accumulation of valuable market and consumer knowledge.

Perhaps the clearest example of the significance of the evolution of knowledge through generations was depicted in the case of Uruguay1. First, four siblings inherited the firm, and each of them undertook a key strategic role of the company. Second, the next generation inherited their father's legacy as heirs accordingly to the business role. One fundamental example was the production of sturgeon feed, which originally was knowledge strictly kept secret by Russian scientists, and later on partly purchased by their father. According to Uruguay1:

We had four different feed formulas depending on the season... a key merit of our father was to convince the Russian scientists to adapt the formula to the available raw materials in Uruguay... We then continued this process and today we have five different formulas: it is an area we have developed on our own.

Clearly, this form of tacit knowledge has significant strategic implications for the firm, notably, in terms of uniqueness and competitive advantage. Equally important were other aspects where knowledge played an essential role. For example, the participant commented that the family firm adapted the original commercial structure it developed when the firm was still a maritime agency: "it was many years selling fish: we know people in all ports and places on earth. If a person we know cannot distribute, he/she will refer us to someone else who can solve our problem."

In line with Chirico's (2008) model, all five cases depict openness factors, in that part of the knowledge was acquired or accumulated externally, and emotional factors, in that the new generation was committed to the family firm and demonstrated psychological ownership. In addition, other important aspects related to knowledge accumulation were revealed. In 
particular, and as the cases of Australia1, UK1 and Uruguay1 show, previous knowledge acted as a vital support in addressing contemporary situations. This knowledge, which was arguably the result of both openness and emotional factors, was influenced by the behaviour of the entrepreneurs, illustrated by their initiative and leadership to continuously accumulate knowledge or engage in trial and error pursuits. As Peru1 noted:

We have considered different processes, trial and error, and have made mistakes, and repeated the exercise, and been able to understand why the results were not as expected. You have to 'live it', search, and choose different possibilities to find a solution to what you are looking for...

The previous paragraphs illustrating the different ways in which knowledge is passed on from one family generation to the next corroborate the significant involvement of previous and current generations of family members, as well as the engagement of 'new' generations. As a result, Proposition 2 was also confirmed.

\section{Discussion}

The applicability of the proposed framework

According to Payne (2018), theory entails simplification of reality, attempts to "explain some relevant components of a phenomenon" (p. 171), and is useful, notably, in helping to predict and understand relationships, guiding future research and behaviours. Similarly, Astrachan et al. (2014) state that the fundamental purpose in theory development is to uncover relationships, strengths and directionality, "as well as observable measures" (p. 118). In line with these notions, the proposed framework (Figure 1) depicts associations between the theory and the study's findings. Moreover, by illustrating the various associations between the assertions of the KBV and the findings, the framework facilitates the understanding of how knowledge develops and extends through the family firm's different generations, and therefore makes a theoretical contribution.

Figure 1 Here

The foundation of the framework is based on five key assertions proposed by Grant (1996, 1997, 2002). Indeed, Grant (2002) posits that various observations and assumptions conform to the foundation of the KBV of the firm, notably, concerning knowledge and its role in production. Moreover, in bringing together contributions from various authors (Arthur, 1994; Kogut \& Zander, 1992; Machlup, 1980; Nonaka, 1994; Shapiro \& Varian, 1999; Simon, 1991), and the work of Grant (1996, 1997, 2002), the following assertions are proposed:

1. Appropriability: While neither explicit nor tacit knowledge are appropriable, they can be kept within humans; this knowledge is developed within a firm, and therefore is firm-specific (Grant, 1996). Moreover, as a productive resource, knowledge is of paramount importance, for instance, concerning its market value (Grant, 2002), and strategic value for enterprises (Grant, 1997).

2. Transferability: Different forms of knowledge vary in the way they are transferable. Indeed, explicit knowledge can be easily communicated or articulated between organisations and individuals, whereas tacit knowledge (know-how, skills) can only be manifested through its application and transferred from individual to individual (Grant, 1996, 2002).

3. Capacity for aggregation: At both organisational and individual levels, knowledge absorption is dependent upon the ability among recipients "to add new knowledge to existing knowledge" (Grant, 1996, p. 111). Efficiencies in aggregating knowledge can be boosted "when knowledge can be expressed in terms of a common language" (Grant, 1996, p. 111). For instance, the advent of technology in the field of statistics has enabled a better transfer of various forms of explicit knowledge (Grant, 1996). 
4. Specialisation: Knowledge is developed by humans; hence, to become efficient in both knowledge storage and creation, people need to specialize in specific areas of knowledge (Grant, 2002).

5. Requirements of production: Typically, many types of knowledge are required to produce goods and services (Grant, 2002). Furthermore, production relies on transforming inputs into outputs, and knowledge is an essential input in the production process and key source of value (Grant, 1996).

First, appropriability is pertinent to all the participating firms, in that knowledge developed and nurtured over the years or decades has become part of the fabric of the firm, and significantly contributes to its strategic value (Grant, 1997). Among other cases, that of Australia1 encapsulates the dimensions of the current generation, which has accumulated vast and extremely valuable industry knowledge and expertise. The new generation, which is progressively becoming integrated into the family firm, is also making strides to make a significant contribution..

Second, transferability of knowledge was reflected, among other ways, through external critical events that radically modified the way the firms operated. The most extreme illustration, depicted by UK1, stresses the impact of explicit knowledge in the aftermath of a devastating situation. Explicit knowledge, communicated among firm members during the months following the foot-and-mouth epidemic, and therefore associated with appropriability of knowledge, was absorbed and dissected by the ownership, which acted based on their own professional knowledge, their expertise, and their mastery of various skills. Over time, tacit knowledge had been developed through the numerous experiences and situations following the experience to become resilient after the epidemic, and passed on to the new generation. Moreover, while still in their first stages of firm involvement, second generation members are integrating new explicit knowledge (social media, marketing, sales skills), which extends from and is based on the firm's tacit knowledge.

Third, capacity of knowledge aggregation was one of two assertions that underlined the strong legacy of the previous or currently most dominant generation of the firm. Moreover, in the absence of any imminent takeover by a younger generation, aggregation is predominantly revealed by different efforts and initiatives, highlighting knowledge aggregation. The case of Uruguay1, for instance, underscores the strong influence by the original founder of the firm, who gathered and accumulated explicit knowledge which was later on converted into tacit knowledge through improvements and enhancements in sturgeon production.

Fourth, efficiency, which can be triggered or enhanced by specialisation in aspects associated with knowledge (Grant, 2002), is arguably a pillar of value creation for the family firm, and was also illustrated in all participating firms. Perul's case, however, symbolises the slow but effective generational transition, with a younger family member accumulating knowledge in a particular field, economics, which can have important implications for the firm. This specialisation of knowledge has contributed to further development of knowledge within the firm, and also has strong links with appropriability, transferability, and aggregation. Indeed, the interview content revealed that the firm specialises in particular aspects of coffee production and sales.

Fifth, the requirements of production assertion postulated by Grant (2002) was also depicted in all the participating firms. For instance, based on interview content, on-site observations, and printed information, Italy1, while formally was established in the 1970s, has a generational line which extends nearly a century. This firm has progressively adopted newer, more modern systems, equipment and technologies, complementing traditional ways. Moreover, while various aspects preceding the final production stage of Prosecco Superiore, such as vineyard management, remain for the most part traditional, modernisation, 
involvement in wine tourism, or more emphasis on exports, demonstrate the consideration and operationalisation of various types of knowledge.

\section{Conclusion}

Part of the academic literature emphasises that prior knowledge is intrinsically related to ways in which entrepreneurs identify new opportunities (Kontinen \& Ojala, 2011). Knowledge is also crucial among family businesses (e.g., Chirico \& Salvato, 2008); Cunningham et al., 2016; Giovannoni et al., 2011). However, still many areas pertaining to family business research have been scantly examined or are still underdeveloped. One example is the apparent prevalence of quantitative research (Nordqvist et al., 2009), hence, the under-realisation of qualitative inquiry (Fletcher et al., 2016), while another is the limited research examining family firms across various geographic settings. By employing a qualitative and case study methodology, and by focusing on family firms operating in different geographic contexts and industries, the present research narrowed these research gaps. The findings underlined the practical and strategic importance of critical events, previous hand-on experience, trial and error, or from networking and collaborating as sources of explicit and tacit knowledge. In all cases, generational involvement was clearly present, either through incremental or full-scale efforts. This involvement denoted ways in which knowledge was extended, complemented or adapted to the firm's needs and objectives.

In addition, the study also addressed a theoretical gap. Indeed, according to Astrachan et al. (2014), there are concerns with constrains in theory specification in family business research. The emerging findings illustrated that the ways in which knowledge was acquired, accumulated and operationalised aligned with the different assertions highlighted in the KBV of the firm. These alignments, which are represented in Figure 1, reinforce the understanding which could be gained by considering this theoretical framework when examining knowledge, particularly its development, integration, and absorption across family firm generations.

\subsection{Implications}

Different practical and theoretical implications can be identified in this study. First, from a practical point of view, the results suggest that family firms should not underestimate the value of previous knowledge and experiences and how these have a role to play in the future. As evidenced from the different case studies, external forces, together with hands-on experience, collaborations and trial and error efforts significantly contributes to a firm's knowledge creation. At times, and as the case of UK1 illustrates, there was a need to call upon previous knowledge as a means to nullify emergent negative forces. Furthermore, all cases demonstrated that it is only through the cumulative effect of historical and previous knowledge that gaps in the marketplace or a viable alternative to exploit them has been identified to enhance the firm's competitive advantage and keep it afloat.

Second, family firms need to not only be aware of the complex and ever-changing environment they operate in, but take check of their internal competencies, capabilities and resources. In this context, knowledge helps build resilience, and it is also likely that small internal shifts or even clear overhauls, when needed, can be undertaken to the benefit of the firm. Third, the study has also identified that there is an active need to innovate and adapt to capture new markets or opportunities. The ability to identify and operationalise these strategies are a product of shared vision and knowledge. There is also much to be learnt from the strong foundation of knowledge built up by previous generations of owners. Fourth, and similarly, there is much to be embedded and incorporated from younger generations, where more contemporary notions could be considered. This implication also reiterates the value of sharing knowledge across generations where wisdom feeds forward and backward, and, as 
illustrated in the present study, is particularly true across different organisational types and industries as well as across different geographic settings.

From a theoretical point of view, following Astrachan et al.'s (2014) notions of theory development, the study has illustrated the numerous relationships between the findings and the KBV of the firm, which culminates in the proposed theoretical framework (Figure 1). Furthermore, the assertions postulated in Grant's work $(1996,1997,2002)$ were found to be aligned with ways in which past, present, and future generations (e.g., Australia1, Peru1, UK1) involved in the firm acquired, transferred, and built knowledge. Thus, one fundamental theoretical implication is that the framework not only depicts a simplification of reality (Payne, 2018), but also helps explain several components of the phenomenon (Payne 2018). In the case of the present research, the framework provides a road map of how knowledge accumulates and transfers through generations. Moreover, while limited to only five family firms, the framework illustrates commonalities and alignments across different geographic contexts concerning the above dimensions of knowledge, which denotes its potential usefulness as a guiding tool in future research.

In addition, the study has identified a particular advantage that can be gained from generational knowledge sharing, which promotes resilience and assists in firm success. This finding has implications for research in understanding firm survival and longevity. Potentially, family businesses have an added advantage and survival should perhaps be viewed from a different perspective as part of competitive advantage gained through generational knowledge. Indeed, it would suggest that firm survival, and with it longevity, is facilitated positively by generational knowledge sharing.

\subsection{Limitations and future research}

While the study adds to the family business literature in various forms, both empirically and theoretically, it is not free of limitations. For example, the study's findings are based upon interviews with five model family firms. Despite their significance as information-rich cases (Patton, 2015), the modest number of participating firms does not allow for making any broad generalisations regarding the development and transfer of knowledge among family firms and their generations. In addition, the study has applied a dominant qualitative methodological approach, and while through this approach rich qualitative data were collected, it does not consider or allow for the testing within the dataset. Thus, it would be useful for future research to utilise data collection approaches to include questionnaires and financial metrics to test for the ability of generational knowledge to affect firm survival and resilience. Considering this alternative line of research could help pinpoint or identify the effect of such knowledge and its related interventions on the financial success of the firm.

Furthermore, while the study has utilised firms operating in different sectors to provide a holistic representation of family businesses, future data collection in this guise, as well as a wider case study group, could help bolster and strengthen the findings here. In addition, while the developed framework suggests implications and extends understanding into family businesses, its generalisability needs to be careful considered and weighted in the context of the sampling considerations of this study. Future research could re-examine the findings of this study against other firms and in other countries to extend on the overall viability of the framework and its suitability.

\section{References \\ References}

Andersén, J. (2015). The absorptive capacity of family firms: How familiness affects potential and realized absorptive capacity. Journal of Family Business Management, 5(1), 73-89. doi:10.1108/JFBM-05-2014-0012 
Arthur, W. B. (1994). Inductive reasoning and bounded rationality. The American Economic Review, 84(2), 406-411. doi:10.2307/2117868

Astrachan, C. B., Patel, V. K., \& Wanzenried, G. (2014). A comparative study of CB-SEM and PLS-SEM for theory development in family firm research. Journal of Family Business Strategy, 5(1), 116-128. doi:org/10.1016/j.jbs.2013.12.002

Boyd, B., \& Royer, S. (2012). The suitability of internal versus external successors: Relevant knowledge types in family business succession. International Journal of Management Practice, 5(4), 361-382. doi:10.1504/IJMP.2012.050315

Boyd, B., Royer, S., Pei, R., \& Zhang, X. (2015). Knowledge transfer in family business successions: Implications of knowledge types and transaction atmospheres. Journal of Family Business Management, 5(1), 17-37. doi:10.1108/JFBM-05-2014-0009

Cabrera-Suárez, K., De Saá-Pérez, P., \& García-Almeida, D. (2001). The succession process from a resource-and knowledge-based view of the family firm. Family Business Review, 14(1), 37-48. doi:10.1111/j.1741-6248.2001.00037.x

Cater III, J. J., \& Justis, R.T. (2009). The development of successors from followers to leaders in small family firms: An exploratory study. Family Business Review, 22(2), 109-124. doi: $10.1177 / 0894486508327822$

Chaudhary, S., \& Batra, S. (2018) Absorptive capacity and small family firm performance: exploring the mediation processes. Journal of Knowledge Management, 22(6), 12011216. doi:10.1108/JKM-01-2017-0047

Chirico, F. (2008). Knowledge accumulation in family firms: Evidence from four case studies. International Small Business Journal, 26(4), 433-462. doi: $10.1177 / 0266242608091173$

Chirico, F., \& Nordqvist, M. (2010). Dynamic capabilities and trans-generational value creation in family firms: The role of organizational culture. International Small Business Journal, 28(5), 487-504. doi: 10.1177/0266242610370402

Chirico, F., \& Salvato, C. (2008). Knowledge integration and dynamic organizational adaptation in family firms. Family Business Review, 21(2), 169-181. doi:10.1111/j.1741-6248.2008.00117.x

Chirico, F., \& Salvato, C. (2016). Knowledge internalization and product development in family firms: When relational and affective factors matter. Entrepreneurship Theory and Practice, 40(1), 201-229. doi:10.1111/etap.12114

Chua, J. H., Chrisman, J. J., Steier, L. P., \& Rau, S. B. (2012). Sources of heterogeneity in family firms: An introduction. Entrepreneurship Theory and Practice, 36(6), 11031113. doi:10.1111/j.1540-6520.2012.00540.x

Conner, K. R., \& Prahalad, C. K. (1996). A resource-based theory of the firm: Knowledge versus opportunism. Organization Science, 7(5), 477-501. doi: 10.1287/orsc.7.5.477

Cope, J., \& Watts, G. (2000). Learning by doing-an exploration of experience, critical incidents and reflection in entrepreneurial learning. International Journal of Entrepreneurial Behavior and Research, 6(3), 104-124. doi: $10.1108 / 13552550010346208$

Cunningham, J., Seaman, C., \& McGuire, D. (2016). Knowledge sharing in small family firms: A leadership perspective. Journal of Family Business Strategy, 7(1), 34-46. doi: $10.1016 /$ j.jfbs.2015.10.002

Danes, S.M., Stafford, K., Haynes, G. and Amarapurkar, S.S. (2009). Family capital of family firms: Bridging human, social, and financial capital. Family Business Review, 22(3), 199-215. doi:10.1177/0894486509333424

Diehr, G., \& Wilhelm, S. (2017). Knowledge marketing: How can strategic customers be utilised for knowledge marketing in knowledge-intensive SMEs? Knowledge Management Research and Practice, 15(1), 12-22. doi:10.1057/s41275-016-0039-1 
Duarte Alonso, A., Kok, S., \& O’Shea, M. (2018). Family businesses and adaptation: A dynamic capabilities approach. Journal of Family and Economic Issues, forthcoming. doi: $10.1007 / \mathrm{s} 10834-018-9586-3$

Efferin, S., \& Hartono, M. S. (2015). Management control and leadership styles in family business: An Indonesian case study. Journal of Accounting and Organizational Change, 11(1), 130-159. doi:10.1108/JAOC-08-2012-0074

Eisenhardt, K. M. (1989). Building theories from case study research. Academy of Management Review, 14(4), 532-550. doi:10.5465/amr.1989.4308385

Elo, S., Kääriäinen, M., Kanste, O., Pölkki, T., Utriainen, K., \& Kyngäs, H. (2014). Qualitative content analysis: A focus on trustworthiness. SAGE Open, 4(1), 1-10. doi: $10.1177 / 2158244014522633$

Fletcher, D., De Massis, A., \& Nordqvist, M. (2016). Qualitative research practices and family business scholarship: A review and future research agenda. Journal of Family Business Strategy, 7(1), 8-25. doi:10.1016/j.jfbs.2015.08.001

Foos, T., Schum, G., \& Rothenberg, S. (2006). Tacit knowledge transfer and the knowledge disconnect. Journal of Knowledge Management, 10(1), 6-18. doi:10.1108/13673270610650067

Giovannoni, E., Maraghini, M.P., \& Riccaboni, A. (2011). Transmitting knowledge across generations: The role of management accounting practices. Family Business Review, 24(2), 126-150. doi:10.1177/0894486511406722

Goh, S. C. (2002). Managing effective knowledge transfer: an integrative framework and some practice implications. Journal of Knowledge Management, 6(1), 23-30. doi: $10.1108 / 13673270210417664$

Grant, R. M. (1996). Toward a knowledge-based theory of the firm. Strategic Management Journal, 17(S2), 109-122. doi:10.1002/smj.4250171110

Grant, R. M. (1997). The knowledge-based view of the firm: implications for management practice. Long Range Planning, 30(3), 450-454. doi:10.1016/S0024-6301(97)00025-3

Grant, R. M. (2002). The knowledge-based view of the firm. In C.W. Choo and N. Bontis (Eds.), The strategic management of intellectual capital and organizational knowledge (pp. 133-148). Oxford, UK, Oxford University Press.

Gronn, P. (2002). Distributed leadership as a unit of analysis. The Leadership Quarterly, 13(4), 423-451. doi:10.1016/S1048-9843(02)00120-0

Hernández-Perlines, F. (2018). Moderating effect of absorptive capacity on the Entrepreneurial orientation of international performance of family businesses. Journal of Family Business Management, 8(1), 68-74. doi:10.1108/JFBM-10-2017-0035

Hernández-Linares, R., Kellermans, F.W., \& López-Fernández, M.C. (2018). A note on the relationships between learning, market, and entrepreneurial orientations in family and nonfamily firms. Journal of Family Business Strategy, 9(3), 192-204. doi:10.1016/j.jfbs.2018.08.001

Hsieh, H-F, \& Shannon, S.E. (2005). Three approaches to qualitative content analysis. Qualitative Health Research, 15(9), 1277-1288. doi:10.1177/1049732305276687

Kogut, B., \& Zander, U. (1992). Knowledge of the firm, combinative capabilities, and the replication of technology. Organization Science, 3(3), 383-397. doi: $10.1287 /$ orsc.3.3.383

Kontinen, T., \& Ojala, A. (2011). International opportunity recognition among small and medium-sized family firms. Journal of Small Business Management, 49(3), 490-514. doi:10.1111/j.1540-627X.2011.00326.X

Letonja, M., \& Duh, M. (2016). Knowledge transfer in family businesses and its effects on 
the innovativeness of the next family generation. Knowledge Management Research and Practice, 14(2), 213-224. doi:10.1057/kmrp.2015.25

Lindh, I., \& Thorgren, S. (2016). Critical event recognition: An extended view of reflective learning. Management Learning, 47(5), 525-542. doi: $10.1177 / 1350507615618600$

Machlup, F. (1980). Knowledge: Its creation, distribution and economic significance (Volume 1). Princeton, N.J.: Princeton University Press.

Marshall, B., Cardon, P., Poddar, A., \& Fontenot, R. (2013). Does sample size matter in qualitative research? A review of qualitative interviews in IS research. Journal of Computer Information Systems, 54(1), 11-22. doi:10.1080/08874417.2013.11645667

Miles, M. B., Huberman, A. M., Huberman, M. A., \& Huberman, M. (1994). Qualitative data analysis: An expanded sourcebook. Thousand Oaks, CA: SAGE Publications, Inc.

Miller, D., Le Breton-Miller, I., Lester, R. H., \& Cannella Jr, A. A. (2007). Are family firms really superior performers? Journal of Corporate Finance, 13(5), 829-858. doi:10.1016/j.jcorpfin.2007.03.004

Mills, J., Bonner, A., \& Francis, K. (2006). Adopting a constructivist approach to grounded theory: Implications for research design. International Journal of Nursing Practice, 12(1), 8-13. doi:10.1111/j.1440-172X.2006.00543.X

Nonaka, I. (1994). A dynamic theory of organizational knowledge creation. Organization Science, 5(1), 14-37. doi:10.1287/orsc.5.1.14

Nonaka, I., \& Takeuchi, H. (1995). The knowledge creating company. New York: Oxford University Press.

Nordqvist, M., Hall, A., \& Melin, L. (2009). Qualitative research on family businesses: The relevance and usefulness of the interpretive approach. Journal of Management and Organization, 15(3), 294-308. doi:10.1017/S1833367200002637

Patel, P. C., \& Fiet, J. O. (2011). Knowledge combination and the potential advantages of family firms in searching for opportunities. Entrepreneurship Theory and Practice, 35(6), 1179-1197. doi:10.1111/j.1540-6520.2011.00497.x

Patton, M. Q. (2015). Qualitative research and evaluation methods ( ${ }^{\text {th }}$ ed.). Los Angeles, CA: SAGE Publications, Inc.

Payne, G. T. (2018). Reflections on family business research: Considering domains and theory. Family Business Review, 31(2), 167-175. doi: $10.1177 / 0894486518776550$

Poza, E. J., \& Daugherty, M. S. (2013). Family business (4 ${ }^{\text {th }}$ ed.). Mason, OH: SouthWestern Cengage Learning.

Prencipe, A., Bar-Yosef, S., \& Dekker, H. C. (2014). Accounting research in family firms: Theoretical and empirical challenges. European Accounting Review, 23(3), 361-385. doi:10.1080/09638180.2014.895621

Reay, T., \& Zhang, Z. (2014). Qualitative methods in family business research. In L. Melin, M. Nordqvist P. Sharma (Eds), The Sage Handbook of Family Business (pp. 573593). London, UK: Sage.

Sciascia, S., Mazzola, P., \& Chirico, F. (2013). Generational involvement in the top management team of family firms: Exploring nonlinear effects on entrepreneurial orientation. Entrepreneurship Theory and Practice, 37(1), 69-85. doi:10.1111/j.1540-6520.2012.00528.x

Shapiro, C., \& Varian, H. R. (1999). The art of standards wars. California Management Review, 41(2), 8-32. doi:10.2307/41165984

Simon, H. A. (1991). Organizations and markets. The Journal of Economic Perspectives, 5(2), pp. 25-44. doi:10.1257/jep.5.2.25

Sinkovics, R. R., Penz, E., \& Ghauri, P. N. (2008). Enhancing the trustworthiness of 
qualitative research in international business. Management International Review, 48(6), 689-714. doi:10.1007/s11575-008-0103-Z

Sirmon, D. G., \& Hitt, M. A. (2003). Managing resources: Linking unique resources, management, and wealth creation in family firms. Entrepreneurship Theory and Practice, 27(4), 339-358. doi:10.1111/1540-8520.t01-1-00013

Sosna, M., Trevinyo-Rodríguez, R. N., \& Velamuri, S. R. (2010). Business model innovation through trial-and-error learning: The Naturhouse case. Long Range Planning, 43(2-3), 383-407. doi:10.1016/j.lrp.2010.02.003

Thomas, D. (2006). A general inductive approach for analyzing qualitative evaluation data. American Journal of Evaluation, 27(2), 237-246. doi: $10.1177 / 1098214005283748$

Wernerfelt, B. (1984). A resource-based view of the firm. Strategic Management Journal, 5(2), 171-180. doi:10.1002/smj.4250050207

Williams Jr, R. I., \& Mullane, J. V. (2019) Family leadership succession and firm performance: The moderating effect of tacit idiosyncratic firm knowledge. Knowledge and Process Management. 26(1), 32-40. doi:10.1002/kpm. 1594

Woodfield, P., \& Husted, K. (2017). Intergenerational knowledge sharing in family firms: Case-based evidence from the New Zealand wine industry. Journal of Family Business Strategy, 8(1), 57-69. doi:10.1016/j.jfbs.2017.01.001

Yin, R. K. (2013). Case study research - Design and methods (5 ${ }^{\text {th }}$ ed.). Thousand Oaks, CA.: SAGE Publications, Inc.

Zahra, S. A. (2005). Entrepreneurial risk taking in family firms. Family Business Review, 18(1), 23-40. doi:10.1111/j.1741-6248.2005.00028.x

Zahra, S. A. (2012). Organizational learning and entrepreneurship in family firms: Exploring the moderating effect of ownership and cohesion. Small Business Economics, 38(1), 51-65. doi:10.1007/s11187-010-9266-7

Zahra, S.A., \& George, G. (2002). Absorptive capacity: a review, reconceptualization and extension. Academy of Management Review, 27(2), 185-203. doi:10.5465/amr.2002.6587995

Zellweger, T., \& Sieger, P. (2012). Entrepreneurial orientation in long-lived family firms. Small Business Economics, 38(1), 67-84. doi: $\underline{10.1007 / s 11187-010-9267-6}$ 